\title{
The Current State of Mongolia's Energy Sector and Prospects for Development with Entry Into the Russian and Nea Energy Markets
}

\author{
S. Batmunkh ${ }^{1,{ }^{*}}$, S. Batkhuyag, P. Ochirbat, H.Enkhzhargal, B. Bat-Erdene, M. Tumenzhargal ${ }^{2}$
}

${ }^{1}$ Academician of the Academy of Sciences of Mongolia

${ }^{2}$ Ministry of Energy of Mongolia

\begin{abstract}
The paper addresses research into the prospects for the development of Mongolia's energy sector with its gradual entry into the international energy markets of neighboring countries through the involvement of local resource potential and the expansion of energy transmission and transportation systems. Rational use of rich primary natural energy resources (coal, solar energy, and nuclear energy), in combination with a favorable geographic location of the country, should contribute to the achievement of the crucial goals to transform Mongolia into an energy exporting-importing country, which is stipulated by the raw materials and energy strategy of the country for the next 15-30 years.
\end{abstract}

In this context, the research considers an integrated approach to the development of the energy system of Mongolia and highlights three hierarchical development levels of backbone transmission lines. The research outcomes are presented as a structure of Mongolia's energy sector with internal and external functional connections. The conclusion emphasizes the need to build a scientifically grounded rational network structure of the main backbone transmission lines, which will shape the Unified energy system with developed connections to the electric power systems of Russia and China, and through them, to the super grid of the NEA countries. This will allow Mongolia to occupy its place in a successfully developing energy and economic space of the region, which is beneficial not only for Mongolia but also for the NEA countries.

Index Terms: energy sector, development prospects, generating capacity, energy system, hierarchical levels of EPS development, an integrated approach to development, Mongolian-Russian energy cooperation, energy strategy.

\footnotetext{
${ }^{*}$ Corresponding author.

E-mail: batmunkh_acad@yahoo.com
}

http://dx.doi.org/10.38028/esr.2020.03.0001

Received April 10, 2020. Revised May 13, 2020.

Accepted June 02, 2020. Available online December 27, 2020.

This is an open access article under a Creative Commons Attribution-NonCommercial 4.0 International License.

(C) 2020 ESI SB RAS and authors. All rights reserved.

\section{INTRODUCTION}

The stable development of the Mongolian economy largely depends on the successful operation of the country's fuel and energy industry, which plays an essential role in meeting the ever-increasing domestic demand for electricity, heat, and fuel. Moreover, it reduces electricity imports to cover the baseload and the need to export fuel and electricity in the future. Thus, the successful operation of the energy sector determines the national energy security, which was, is, and remains a very urgent task. In the light of modern environmental and other requirements, this task cannot be accomplished only through the modernization and expansion of the exploitation of existing coal mines and the development of new coal deposits, as well as the modernization and expansion of existing coal-fired power plants and construction of new ones. Although, these ways are necessary conditions for strengthening the named branches of the Mongolian economy.

For reference. Since 1995, private mining companies have been widely involved in the mining sector. Since 2000, their activities have expanded to the mining and export of coal. More than 30 coal deposits are currently being developed. Large-scale coal mining is carried out only in the Central and Southern regions. Mongolia's mining industry fully meets the domestic demand for coal. The main consumers are power plants, which account for about $80 \%$ of the total coal demand.

The expansion of Ulan Bator CHPP-3, CHPP-4, and Darkhan CHPP with cogeneration units, and the installation of new turbine generators at the thermal power plant of the Erdenet Mining and Processing Integrated Plant in recent years have although increased the available capacity by about $300 \mathrm{MW}$, still have not improved much the overall efficiency of the energy sector, and contributed only to an increase in the reliability of electricity and heat supply to cities, which is undoubtedly a significant aspect of energy supply. The shortage of available capacity of existing power generating sources has been especially strongly felt in recent years during the period of winter maximum electrical loads.

Given the modern requirements of stable development and environmental safety, this problem can be solved by 


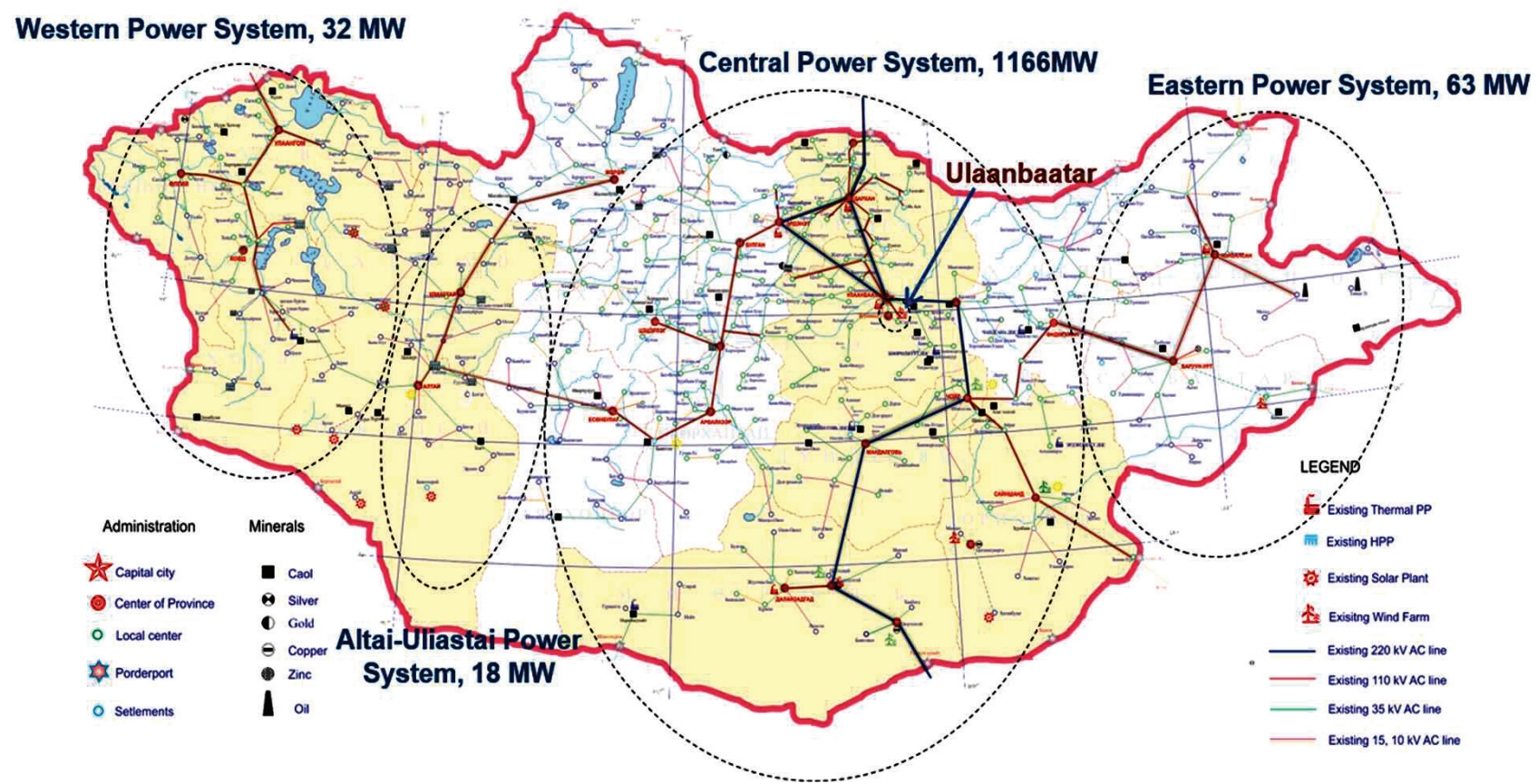

Fig.1. Electric power systems of Mongolia and a scheme of backbone transmission lines (as of 2020)

involving alternative types of energy resources available in the country. These resources are wind, solar and hydro.

Before deciding on what direction to choose for the development of the resource base and the expansion of generating capacities of Mongolia's energy systems, one should analyze the current state and existing situation in the energy and fuel industry of the country.

\section{CURRENT STATE OF MONGOLIAN ELECTRIC POWER SYSTEM}

New legal framework for the activities of entities with various ownership forms, the attraction of foreign investment in the energy sector of Mongolia in 2001-2013, and an increase in the state budget funds allocated for the development of energy facilities as of 2020, made it possible to increase the total installed capacity of power plants of all the electric power systems in Mongolia to 1,472.0 MW and the length of $220 \mathrm{kV}$ and $110 \mathrm{kV}$ transmission lines to $7,436.6 \mathrm{~km}$ (Table 1). There are also qualitative improvements in the technical equipment at these facilities and in the state of the electric power systems. At the same time, the real available capacity does not exceed $1000 \mathrm{MW}$.

Table 1. Characteristics of generating capacity and structures of the power transmission lines of the electric power systems within the unified energy system of Mongolia

It is also worth noting that the structure and configuration of the main part of the Mongolian energy system, formed as a result of the construction and commissioning of new power transmission lines in the period from 1997 to the present day, almost fully correspond to the general scheme $[1,2]$, developed in the last stages of socialist construction (Fig. 1).

Eastern electric power system - Southern electric power system - Altai-Uliastai electric power system - Western electric power system - Central electric power system

The total electricity generated in Mongolia in 2019 was 7,003.3 million $\mathrm{kWh}$, and the country imported 1,715.8 million kWh of electricity. As evidenced by an analysis of electricity generation by the structure of generating capacity, $91 \%$ of electricity was produced at thermal power plants (TPPs), consisting mainly of combined heat and power plants (CHPPs), 8.1\% - at solar (SPPs) and wind power plants (WPPs), 1.2\% was generated by hydropower plants (HPPs) and 0.04\% - at diesel power plants. Hence, as is seen, the cogeneration capacities are decisive in the mix of generating capacities, and their electric load depends on the heat load of cities, and not only during their operation in winter but also in summer. In this situation, the EPS can hardly be maneuverable, which is necessary due to the uneven daily electrical load curves. The strong interconnection between electrical and thermal power at CHPPs, the lack of flexible capacities significantly complicate the reliable and high-quality supply of electricity to consumers.

Therefore, it is necessary to introduce thermal condensing and hydraulic capacities in the structure of basic generating capacities and, along with these, create various kinds of peak capacities. The construction of a hydroelectric power plant in the northern region of Mongolia plays an important role here. Design and technical work for the construction of such a plant in the Selenga river basin was carried out in due time by Soviet $\mathrm{R} \& \mathrm{D}$ and design organizations.

Currently, Mongolia lacks effective mechanisms to stimulate the commissioning of energy sources designed to cover peak and semi-peak loads of power systems and to attract private and foreign investment for these purposes. At the same time, Mongolia has some experience in 
Table 1. Characteristics of generating capacity and structures of the power transmission lines of the electric power systems within the unified energy system of Mongolia.

\begin{tabular}{|c|c|c|c|c|c|c|c|}
\hline \multirow[t]{2}{*}{ № } & \multirow[t]{2}{*}{ Electric power system (EPS) } & \multirow{2}{*}{$\begin{array}{l}\text { Total installed } \\
\text { capacity, MW }\end{array}$} & \multicolumn{5}{|c|}{ Voltage level of transmission lines, $\mathrm{kV}$} \\
\hline & & & 220 & 110 & 35 & 15 & 10-6 \\
\hline 1 & Central EPS & $1,222.9$ & $1,617.26$ & $3,825.68$ & 6,197 & 1,694 & 9,619 \\
\hline 2 & Eastern EPS & 36 & - & 845 & $1,232.14$ & 604,49 & 694.2 \\
\hline 3 & Western EPS & 12 & - & 913.7 & 977.8 & 912,8 & $1,497.4$ \\
\hline 4 & Altai-Uliastai EPS & 19,1 & - & 253 & 929 & 533 & 525 \\
\hline 5 & $\begin{array}{l}\text { Southern EPS (Electric grid of } \\
\text { Southern district) }\end{array}$ & 182 & $-{ }^{*}$ & $-{ }^{*}$ & 431 & 161 & 236 \\
\hline & TOTAL & $1,472.0$ & $1,617.26$ & $5,819.38$ & $9,766.94$ & $3,905.29$ & $\overline{12,571.6}$ \\
\hline
\end{tabular}

years (since 2007), there has been a stimulating tariff policy for renewable energy sources stipulated by the Law on Renewable Energy [3]. The implementation of this policy has increased the installed capacities of WPPs and SPPs in recent years. The cost of a unit of installed capacity of these sources sharply decreased in 2019 , therefore changes were made to the tariff setting system for electricity received from these sources connected to the power system [3].

For reference. New capacities (over $200 \mathrm{MW}$ ) that have been built and commissioned to date, namely, wind and solar power plants, not only do not increase the maneuverability of the energy system but also make it even less dynamic and flexible. Therefore, to regulate and cover the peak power, it is necessary to have a hydroelectric power plant or other peak regulating system batteries such as pumped storage power plant and capacitor storage.

The daily electrical load of Mongolian energy systems is uneven in nature, both in winter and in summer. For example, for the Central energy system, the difference between the evening maximum and the night minimum is 280-350 MW (30-35\%).

The state energy strategy [4] suggests that the share of electricity sources based on the renewable energy resources in the total generating capacity should be increased to $20 \%$ by 2020 and up to $30 \%$ by 2030 to provide stable and sustainable development of the country and to reduce the production of greenhouse gases and other harmful emissions from the energy sector. The coal power industry should also pay attention to the introduction of new environmentally friendly technologies, such as coal combustion in boilers with a circulating fluidized bed and/ or with a vortex furnace. As for the coal-fired electricitygenerating sources intended for the electricity export, these should be an environmentally friendly thermal power plant (EFTPP) with one of the specified coal combustion technologies and the subsequent complete processing of all waste into end products of consumer quality [5]. To implement this decision, the Government of Mongolia and the Ministry of Energy need to pursue a unified, consistent, and purposeful integrated approach, taking into account both the development and deployment of productive forces and the transformation of the country's energy sector itself.

Mongolia is known to be rich in mineral resources, including high-quality coal $[6,7]$. The export of goods is of great importance to the national economy. More than $80 \%$ of exports are raw materials: copper concentrate, gold, coal, zinc and iron ore, oil. In recent years, coal has surpassed the export of other goods and become the most important export product to support the national financial system [8]. Mongolia is a relatively new coal exporter. The growth of coal production began in 2004, mainly for export to China. It is still Mongolia's main market for coal exports. In 2018, coal exports amounted to $62 \%$ of the total production [8]. Coal export revenue continuously grows. In 2018, it amounted to USD 2.8 billion, which is $23 \%$ higher than in 2017 [9]. Therefore, Mongolia seeks to increase the export of these resources by expanding foreign trade with the countries of North-East Asia (NEA). To this end, Mongolia has begun the work aimed at extending the railway network, which will allow some promising strategic deposits of mineral resources, including uranium, which are close to the railway, to be involved in the economic activity. Rational use of rich primary natural energy resources in the form of coal, solar energy, and nuclear raw materials in combination with a favorable geographic location of the country should contribute to the achievement of the most important goals stipulated in the raw materials and energy policy of Mongolia to transform the country into an energy exporting-importing country. The intensification of discussions on the issue of the 'Power of Siberia-2' gas pipeline running through Mongolia's territory since last year can also be seen as a new direction for the development of energy cooperation between Mongolia and neighboring countries. Furthermore, the implementation of this project may, to a certain extent, change the view on the structure of the fuel and energy balance of Mongolia.

The expected commissioning of new mines and mining-and-processing entities, as well as the growing power consumption in the social sphere of the southern, southeastern, and eastern regions and in general throughout 


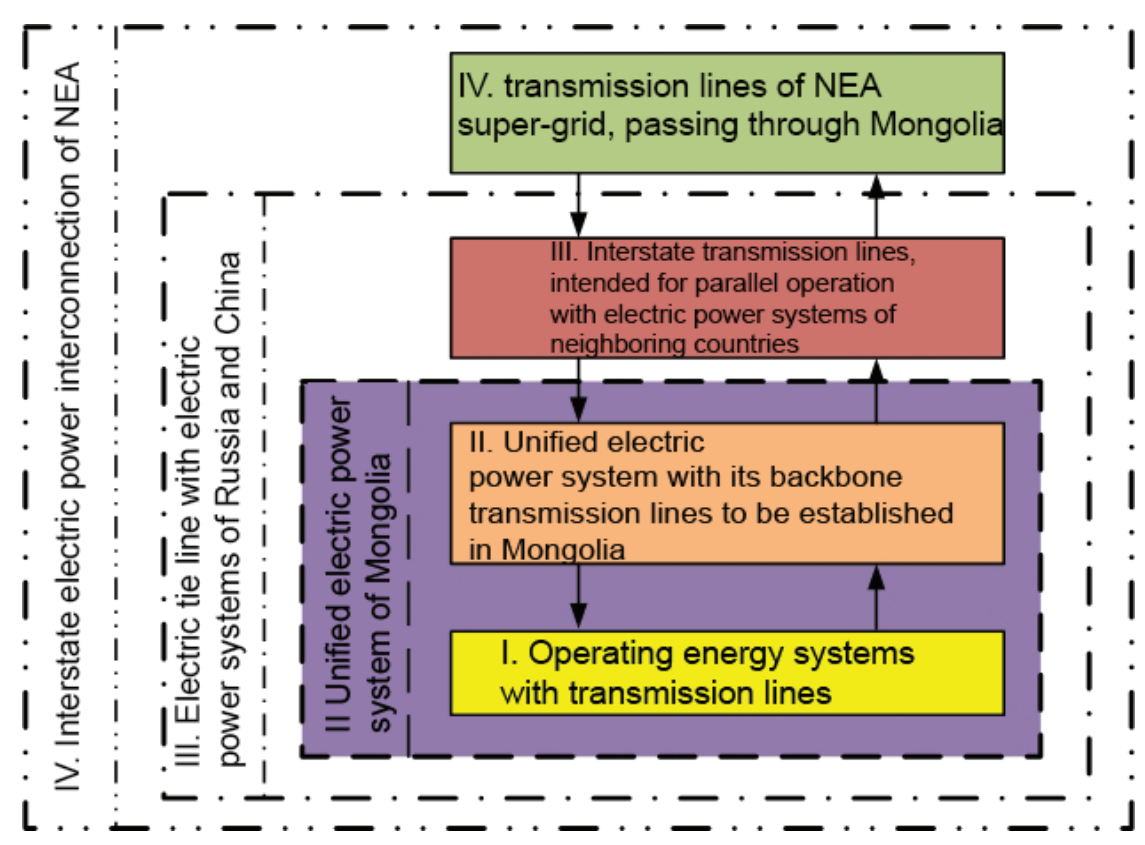

Fig. 2. Hierarchical scheme of the development of Mongolia's electric power system.

the country, lead to a significant increase in demand for electric power. Stabilization of the socio-political situation, and, as a consequence, the economic growth in the country over the previous ten years, increased the average annual electricity production by more than 100 million $\mathrm{kWh} /$ year. Before 2000, the average annual growth had been 3.8\%, and since 2000 , there has been a stable increase in annual electricity production, which averages 236 million $\mathrm{kWh} /$ year, or about $5 \%$ per year. This, and the commissioning of new generating capacities in the near future, require the connection of the country's peripheral energy systems to the largest Central energy system by new power lines, which is a prerequisite for creating the basis for building a unified energy system of Mongolia.

\section{AN INTEGRATED APPROACH TO ENERGY DEVELOPMENT OF MONGOLIA}

Scientifically and practically, this integrated approach to the development of the Mongolian energy sector, including the creation of new generating capacities and new backbone transmission lines, both technically and temporally, is divided into two levels of implementation. The first level provides an increase in the reliability and sustainability of the internal energy supply. The second one is oriented (preparation for the orientation) towards electricity export-import supplies and integration into the interstate electric power interconnection of the NEA countries. Methodologically, however, we can distinguish four hierarchical levels of development throughout the system as a whole (Fig. 2). The first is the currently existing energy systems, the second is the Unified energy system of Mongolia, the third is an energy system operating in parallel with the energy systems of neighboring countries, and the fourth is a component of the international energy interconnection based on the super grid of the NEA countries.

The solutions to be obtained at each level should be organically linked with each other, and one should be a continuation of a previous level and an output of a higher level of hierarchical development of the country's unified energy system. To solve the above issues of the development of energy systems and the establishment of a unified energy system of Mongolia on scientific grounds, the researchers of Mongolia conduct joint scientific research in collaboration with the scientific teams of the SB RAS (Melentiev Energy Systems Institute and Kutateladze Institute of Thermophysics) [5,13-16].

Energy companies holding licenses for the development of coal deposits offer many projects for the construction of condensing power plants of various capacities at large coal mines. However, to date, none of these proposals has been practically implemented. Here it is worth noting that the implementation of such projects, firstly should fit in the location and capacity of the general scheme of the unified energy system, satisfy the demand for electricity output and operating conditions, and secondly, should comply with the technical and economic requirements of the coordination and regulatory authorities of the country's energy sector. At the same time, under the current circumstances, the construction of large condensing capacities, especially under the terms of a concession, is not advisable since neither consumers nor the energy system is prepared to receive a large amount of electricity they produce. For example, the $700 \mathrm{MW}$ condensing capacity, consisting of two $350 \mathrm{MW}$ units, to be constructed at the Baganur coal mine, does not yet fit into the operating conditions of the Central energy system, whose generating capacities consist mainly of combined heat and power plants producing 


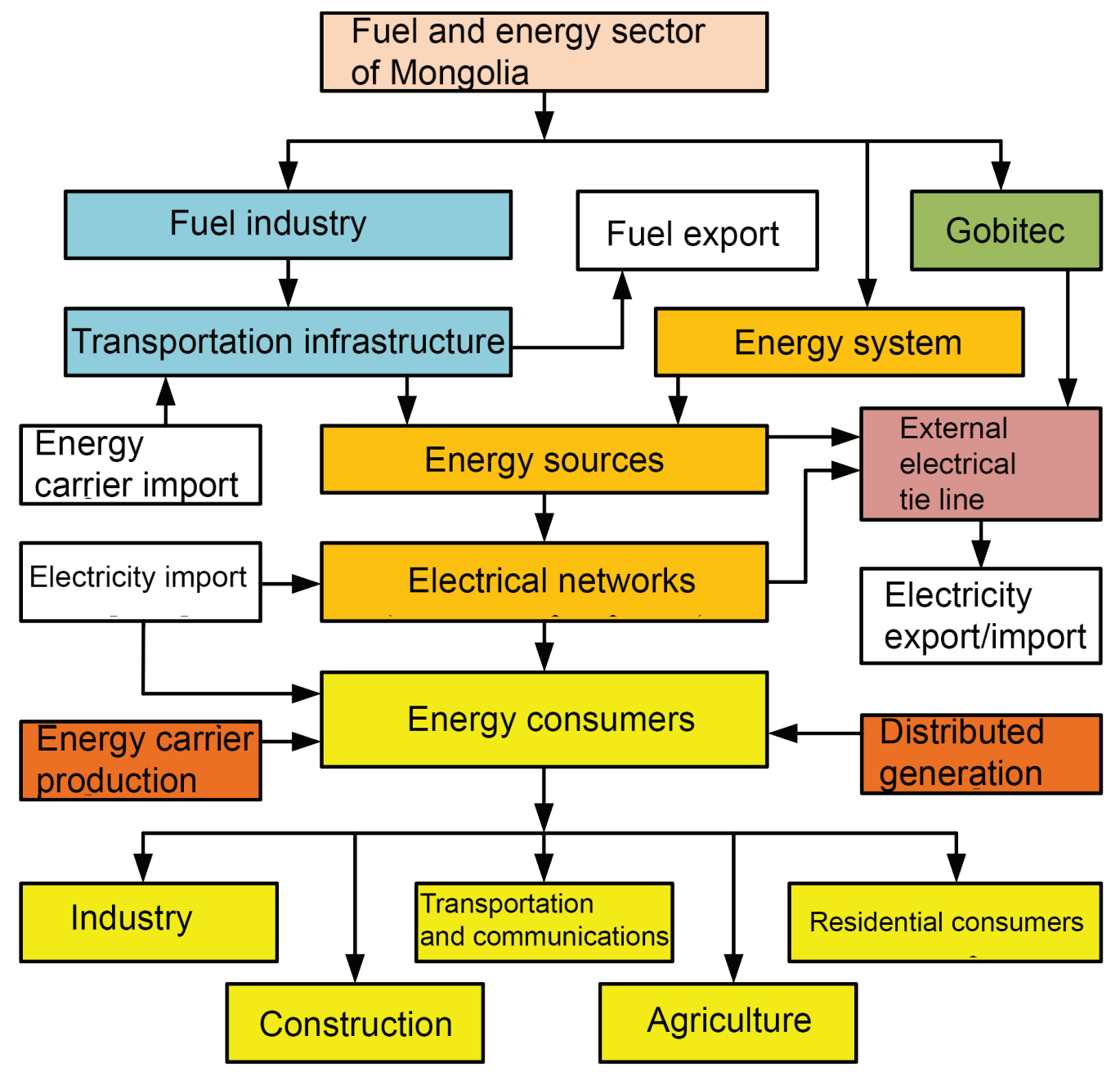

Fig. 3. Block diagram of the fuel and energy complex of Mongolia

electricity and heat. Therefore, in the current situation, to have a short-term solution to the problem of providing the Central energy system with generating capacity, it is necessary along with the construction of a condensing power plant and hydropower plant (in the future, there may be a nuclear power plant) to technically reinforce the electrical tie with the Russian power system. Thus, electricity import from the Russian Federation has been and remains one of the essential issues for the Central energy system and other energy systems (for example, Western ES) in Mongolia.

Traditionally, Mongolia has extensive experience in the economic and energy cooperation with Russia, which continues. The priority areas of mutually beneficial energy cooperation between Mongolia and Russia are still in the coal industry and the electric power industry. In the coal-mining sector, Russia and Mongolia can significantly expand their cooperation through the implementation of a joint project for the development of the world's largest Tavan Tolgoi coking coal deposit [5]. The Mongolian parliament approved [6] the construction of a 1.1 thousand $\mathrm{km}$ railroad from the Tavan Tolgoi deposit to the Russian border for the possible export of the deposit's coking coal to the markets of the Asia-Pacific region (APR) countries through Russian Far Eastern seaports. A mutually beneficial area of cooperation between the two countries in the coal sector is the creation of joint ventures for the comprehensive and advanced processing of Mongolian brown coal. The cooperation of the two countries in the electric power industry is possible in two directions: the reconstruction of existing equipment and the construction of new power plants and the reinforcement of the interstate electrical tie line. Here it is noteworthy to mention the Russian-Mongolian initiative to establish an interstate electric power system Russia-Mongolia-China [10] and form the Asian Super Grid [11, 12]. In recent years, with the participation of Russian energy machine-building companies, work has been continuously carried out to upgrade turbine generators and expand the heating capacity of Ulan-Bator CHP-4. Russia is the major supplier of petroleum products to the Mongolian market.

Mongolia will be a reliable participant in the energy space of the NEA countries. With the creation of such a large-scale system, the construction of large generating capacities operating for the export of electricity, such as the environmentally clean Shive-Ovoo coal-fired thermal 
power plant with a capacity of, for example, $4800 \mathrm{MW}$, becomes justified [5]. The implementation of these projects will contribute to the mutually beneficial energy cooperation with the countries of the region and help cope with the reliability problems of the unified energy system and energy supply of Mongolia.

As a result, the developed fuel and energy sector of Mongolia will be represented by the following structure (Fig. 3), which reflects, approximately, all internal and external functional connections of its components.

At the same time, the above issue of reinforcing the external electrical tie of the Unified energy system of Mongolia will arise, which will affect the interests of Russia and China and increase the opportunities for our country to enter the international energy market and become one of its energy trade partners. Mongolia will also have to solve the problems, first of all, concerning the investment in newly created energy facilities at all hierarchical levels and the cost of electricity produced, and answer the questions whom to sell it, at what price, and others. Nevertheless, we should find positive solutions to problems both for the common interests of the region and for individual countries in the light of cooperation and sustainable development. The transboundary power transmission lines under construction, which are intended to strengthen the external tie line of the Unified energy system of Mongolia, can also be used to export electricity from Russia to China. When the transnational electric power network and the energy interconnection of the NEA countries becomes a reality, it will be possible to implement the most optimal operating parameters of all energy sources in these countries and provide an uninterrupted and reliable power supply at minimal costs.

\section{CONCLUSIONS}

1. The development of Mongolia's unified energy system is an urgent issue, first of all, for this country and the countries of Northeast Asia. At present, it represents five disparate power systems and has limited opportunities for participation in interstate energy cooperation with the NEA countries.

2. Prospective plans for the development of mining deposits and the active building of the industrial and social spheres and housing complex in Mongolia require the creation of a new level of the energy sector with its most significant direction towards the unified energy system with developed external ties, allowing the country to enter the international energy markets.

3. The goal of the research is to design a scientifically grounded rational network structure of the backbone power transmission lines to form the unified energy system and to provide state investment for its implementation.

4. Meeting the domestic demand for electricity in the coming fifteen-year period requires at least 3
GW of capacity (2.5 times more than the existing capacity) to be commissioned and more than 1000 $\mathrm{km}$ of backbone power transmission lines with a voltage of over $220 \mathrm{kV}$ to be constructed. It is also essential to reinforce the interstate electric tie lines with Russia and China.

5. Mongolia's participation in the economic and energy cooperation of the NEA countries with its rich reserves of mineral resources, including highquality coal and high solar energy potential, is beneficial for the countries in the region and serves their common interests.

\section{REFERENCES}

[1] Scheme of power supply of the Mongolian People's Republic for the period 1985-1990, taking into account the development prospects until 2000. Volumes 1-2 and 1-3 (Energosetproekt) and Vol.4-1 (Hydroproject). Leningrad, 1984.

[2] Concept of scientific and technical progress in the fuel and energy industry of the Mongolian People's Republic for the period up to 2005. NIPITEP MTEP. Ulan Bator, 1986, 102 p.

[3] Mongolian Law: Renewable Energy Law (adopted in 2007 and amended in 2015 and 2019). https://www. legalinfo.mn/law/details/465

[4] State Energy Policy for 2015-2030. Resolution of the State Great Khural No. 63 dated June 19, 2015. Ulan Bator. 2015.

[5] S. Batmunkh, V. V. Salomatov, V. A. Stennikov, H. Enkhzhargal. Environmentally friendly coal-fired TPP in the concept of a multi-complex with integration into the electric power system of Mongolia (monograph). MSUST, Kutateladze IT, Melentiev ESI SB RAS. Novosibirsk, 2018.377 p.

[6] P. Ochirbat. Coal industry of Mongolia: state and development prospects // Notes of the Mining Institute. 2017.vol. 226, pp. 420-427.

[7] P. Ochirbat. Development strategy of the mineral resource complex of Mongolia. Published in the Russian Federation, 2007.

[8] Foreign trade / Mongolian Statistical Information Service, 2019. Available at: https://www.1212.mn/ Stat.aspx?LIST_ID=976_L14\&type=tables

[9] Socio-Economic Situation of Mongolia // Monthly Bulletin of Statistics. 2018. No. 11. - 152 p.

[10] Voropai N.I., Saneev B.G., Batkhuyag S., Enkhzhargal H. Energy cooperation between Mongolia and Russia: current state and strategic directions (results of the Russian-Mongolian scientific project 2011-2012). Spatial economics, 2013, no. 3, pp.108-122.

[11] Voropai N.I., Podkovalnikov S.V., Saneev B.G. Interstate cooperation in Northeast Asia: status, potential projects, energy infrastructure. Moscow: Energy Policy, 2014, no. 2. pp. 55-64.

[12] Minutes of the 22nd meeting of the Intergovernmental Russian-Mongolian Commission on Trade, Economic, 
Scientific and Technical Cooperation dated May 30, 2019, Ulan Bator. 22p.

[13] H.Enkhzhargal, S. Batmunkh, V.A. Stennikov. Prospective directions of development of the electric power system of Mongolia. Energy Policy, no. 4, pp.70-80. Moscow. 2012.

[14] B. Bat-Erdene, S. Batmunkh, N. I. Voropai, V. A. Stennikov. Some issues of Mongolia's energy development strategy / Energy Policy, no. 6. pp. 95105. Moscow. 2016.

[15] Batmunkh S., Stennikov V.A., Saneev B.G. Strategic directions for the development of the electric power industry in Mongolia. Moscow: Proceedings of RAS, Power Engineering, no. 6. 2019. pp.51-65.

[16] B. Bat-Erdene, S. Batmunkh, N.I. Voropai, V.V. Selifanov, V.V. Trufanov. Research and analysis of strategies for the development of the electricity industry of Mongolia: Disregarding external international electric tie lines and rejecting the construction of the Eg hydroelectric power plant in the north // Energy (to appear). The study was supported by the international grant of the Russian Foundation for Basic Research (project No. 18-510-94006) and the Ministry of the ECSS of Mongolia (project No. ShuGkh/ OKhU/ 2018/26).

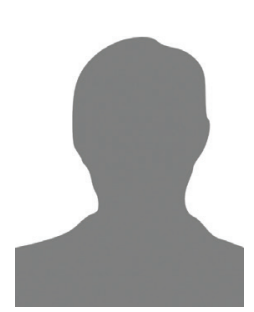

Sereeter Batmunkh, academician, Dr.Sc, full member of the Mongolian Academy of Sciences, professor of Mongolian University of Science and Technology,

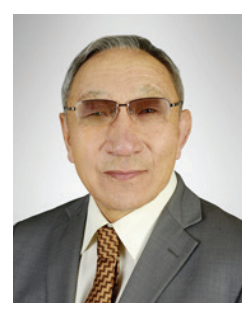

Sodov Batkhuyag, professor, Sc.D, professor of Mongolian University of Science and Technology.

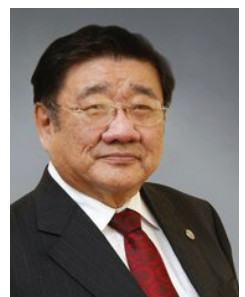

Punsalmaa Ochirbat, academician, Sc.D, full member of the Mongolian Academy of Sciences, professor of Mongolian University of Science and Technology.

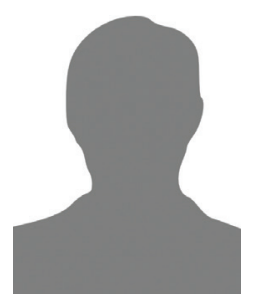

Khaltar Enkhjargal, academician, Sc.D, full member of the Mongolian Academy of Sciences, vice-rector of Mongolian University of Science and Technology.

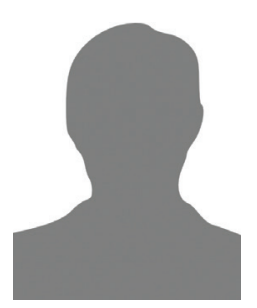

Bayar Bat-erdene, Ph.D. Ass. Professor, Head of "Electro technique" of Mongolian University of Science and Technology Department.

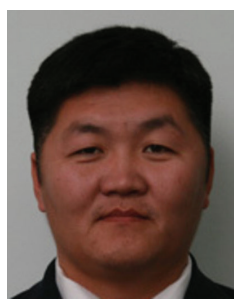

Makhbal Tumenjargal, Director of Mongolian Energy Economics Institute. 